\title{
Política, género y formación: las críticas al normalismo en su período de expansión (1884-1920)
}

\section{Resumen}

El trabajo recorta y analiza una serie de discursos y debates que se dieron sobre el normalismo en el período 1884 a 1920. En esos años las escuelas normales se multiplicaron por todo el territorio nacional y esto dio lugar a que distintos actores cuestionaran las características que estas estaban asumiendo. El artículo se concentra en los discursos de intelectuales y funcionarios ligados a la gestión educativa y se propone mostrar que la figura de la maestra y el maestro normal se construyó en la Argentina como ocupación profesional en el telón de fondo de una serie de discursos sumamente críticos que impugnaban el mecanismo que se utilizaba para formar al magisterio. El texto se focaliza sobre tres aspectos de las criticas que se hacían a las escuelas normales: la influencia de la política, la formación impartida y el perfil femenino que adoptaba tanto la población de las escuelas normales como el magisterio en ejercicio. A través del análisis de estas tres criticas el trabajo pretende contribuir a un entendimiento de las representaciones que se fueron tejiendo en torno a la figura de la maestra y el maestro de escuela. 


\title{
Politics, Gender and Training: Criticisms to Normal Schools in its Period of Expansion (1884-1920)
}

\begin{abstract}
This article analyses a series of debates that took place in Argentina on the topic of normal schools during the period between 1884 and 1920. In those years, normal schools multiplied throughout the national territory and this nourished a public debate on the characteristics of this process. The article focuses on the discourses of intellectuals and civil servants who in most cases were related to the management of schools. The essay aims to show that the figure of the schoolteacher was built in Argentina as a professional occupation in the background of a series of highly critical discourses that expressed doubts about the quality of schoolteachers in the country. The text focuses on three aspects of the criticisms made to normal schools: the influence of politics, the training provided and the female profile adopted by both the normal school population and the practicing teachers. Through the analysis of these three critiques, the work aims to contribute to an understanding of the representations that were woven around the figure of the schoolteacher.
\end{abstract}

Keywords: Normal Schools, Teaching professionalization, Teaching, Feminization, Intellectuals.

\section{Introducción}

Entre 1884, que es cuando se sanciona la ley de educación común en Argentina, y 1920 el Estado fundó según estadísticas oficiales más de 80 escuelas normales destinadas a formar maestros (Gvirtz, 1991, Fiorucci, 2014, Rodríguez, 2019). Algunos de estos establecimientos tuvieron una existencia errática en sus primeros años, no obstante, la cifra aventajaba con creces lo realizado por otras naciones latinoamericanas en ese mismo período. ${ }^{2}$ El ahínco del Estado argentino por crear escuelas normales se explicaba por la necesidad de contar con docentes diplomados para el recientemente creado sistema de instrucción pública. La apuesta se sostenía sobre dos convicciones relacionadas: por un lado, la que postulaba que la escuela primaria constituía el más eficiente agente para promover el progreso, formar la nación y al ciudadano y, por el otro, la que identificaba al maestro como la única garantía para una buena escuela. ${ }^{3}$ En 1914, promediando el final del período estudiado, Manuel Gálvez, quien ya para ese entonces era un reconocido escritor en Argentina, publicó la novela La maestra normal (Gálvez, 1914). En ese

2 En México en 1878 había 12 escuelas normales (un número similar a Argentina en ese momento) tres décadas después, México tenía 26 escuelas normales, mientras que en Argentina ya se habían fundado 46 escuelas normales. En Chile -donde se había creado la primera escuela normal de América Latinahabía cuatro en 1880 y 17 en 1927. En Uruguay hasta mediados del siglo XX solo había una escuela con dos secciones, una para hombres y otra para mujeres. En Venezuela el desarrollo del normalismo fue muy errático y tardío. A principios del siglo XX había dos escuelas normales. Lafarga Galván (2012). Ponce de León, Ren y Uzcátegui Pacheco y (2020: 35-62). Serrano, Ponce de León y Renfiga (2013).

3 La importancia asignada a la escuela y al docente como garantías para el progreso y la nación constituían lugares comunes de la época. Larsen (2011), Lionetti (2007). 
texto que -según el propio escritor- tuvo una amplia acogida del público, Gálvez realizaba una despiadada crítica al normalismo como sistema para formar maestros. En la novela, escrita según el modelo del realismo y apelando a los motivos del nacionalismo de la época, Gálvez describió a la escuela normal como un espacio inmoral, peligroso para las mujeres, corrompido por la politiquería y escenario de una enseñanza mediocre y vulgar. Desprovista de educación religiosa, la escuela normal se había convertido en un lugar donde en su visión se condensaban gran parte de los males sociales de la Argentina de esa época. La novela impugnaba, por lo tanto, las bases sobre las que se había estructurado la apuesta estatal en el terreno educativo cuestionando al mismo tiempo al mecanismo y a la figura que debía sostener ese proyecto.

La maestra normal no pasó desapercibida y fue cuestionada por su contenido tanto por los propios normalistas como por otras figuras del mundo intelectual. En clara alusión a lo proferido por Gálvez, aunque sin nombrarlo, la educadora Rosario Vera Peñaloza reivindicaba unos meses después de aparecido ese texto a la figura de la maestra. En un discurso de graduación dirigido a futuras docentes y reproducido por El Monitor de la Educación Común (la revista del Consejo Nacional de Educación) Peñaloza afirmaba que "confunden su personalidad quienes la encarnan en la caricatura ridícula de un ser hambriento y haraposo de cuerpo y hasta de alma". A la vez exhortaba a las egresadas a "no contaminarse con las miserias de la vida" (Vera Peñaloza, 1915: 493). Casi al mismo tiempo, en noviembre de 1915, un grupo de educadores fundó en Catamarca una revista educativa titulada La maestra normal. En el primer número de esa publicación participó Leopoldo Lugones. La colaboración no fue casual ya que Lugones había esgrimido en el diario La Nación en junio de ese mismo año una airada defensa del normalismo y un cuestionamiento a Gálvez. ${ }^{4}$ La nota de Lugones describía a la "escuela normal como un elemento superior de cultura y hasta el primero de todos en lo referente a la enseñanza primaria" (Lugones, 1915). Lugones pasaba por alto las ácidas apreciaciones que había hecho de la institución normalista en su obra Didáctica publicada en 1909. Con esta operación Lugones no solo ocultaba lo que antes había escrito, sino que aislaba la novela de Gálvez del contexto discursivo del que había emergido. En La maestra normal Gálvez retomaba una discusión que llevaba años y la que este trabajo se propone iluminar. Las diatribas de Gálvez recogían argumentos, críticas e ideas que habían sido ya postuladas por otras figuras y en su conjunto dibujaban un panorama más desalentador sobre el estado de la enseñanza normal que aquel que las estadísticas aisladas podían pintar.

Los cuestionamientos al normalismo aparecieron temprano durante el proceso de expansión de las escuelas de formación docente y persistieron durante todo

4 La nota de Lugones en La Nación respondía a la crítica que había hecho Miguel de Unamuno en las páginas del diario defendiendo las tesis de Gálvez sobre el normalismo. Luego de esa nota, apareció la respuesta de Gálvez donde este afirmó que era un texto de ficción y que su intención no era atacar el normalismo. La novela dejaba entrever los reclamos de los sectores cercanos a la iglesia católica (representados por Gálvez) frente a la pérdida de poder que representaba para la iglesia católica la difusión de las escuelas normales. A la escuela normal se le había asignado una misión moralizadora de la juventud que luego se debía irradiar al cuerpo social. De esta misión había sido excluida la iglesia. Lugones -en contraposición a Gálvez- defendía el ideal laico de la educación. Sobre este tema ver Lionetti (1999). Sobre la polémica en La Nación ver Goldchluk (1995: 23-61). 
el período. Los informes generales advirtieron sobre los problemas de este tipo de instrucción desde principios del siglo XX. En 1902, el pedagogo Pablo Pizzurno, quien actuaba en ese momento como inspector de enseñanza secundaria y normal, abrió su reporte anual afirmando que la educación que recibían los futuros maestros era "deficientísima ... desde el punto de vista de la instrucción, de la calidad y solidez de los conocimientos" pero también de la "formación de hábitos morales" (Pizzurno, 1902: 3). Pasada poco más de una década, en 1916, los inspectores de las escuelas normales llegaban a la misma conclusión en un informe presentado al ministro afirmando que esas instituciones estaban "en crisis" (Inspección General de Enseñanza Secundaria Normal, 1916). Este trabajo se propone iluminar algunas de las zonas más prominentes del debate sobre el normalismo en las décadas en que este se expandió por primera vez en Argentina. La bibliografía sobre el tema del normalismo es copiosa y heterogénea en cuanto a los temas de estudio. ${ }^{5}$ Diversas investigaciones han examinado los objetivos políticos e ideológicos de este proyecto vinculándolo al proceso de consolidación del Estado nacional. ${ }^{6}$ Asimismo, otras indagaciones se han dedicado a analizar el tipo de formación que este tipo de escuelas impartían, lo que ha permitido cuestionar las visiones que postulaban la hegemonía del positivismo entre las tendencias pedagógicas dominantes en esa enseñanza. Más recientemente se ha reconstruido la expansión material de los establecimientos normalistas a lo largo del territorio nacional, a lo que se han sumado análisis acotados a figuras particulares y/o a contextos específicos. Estos estudios han permitido complejizar la historia y el impacto de las escuelas normales a nivel local, ofreciendo una imagen más plural de lo que fueron las primeras décadas de la expansión del normalismo en Argentina. ${ }^{7}$ El estudio de los debates alrededor de esta institución ha ocupado un espacio menos prominente entre las temáticas estudiadas, no obstante, sí existen algunas investigaciones que son retomadas a lo largo del artículo. Entre estas se destacan el trabajo de Lucía Lionetti, quien brinda un análisis de estas discusiones en el marco de un estudio más amplio sobre la construcción de la ciudadanía a través de la escuela, y el estudio de Ricardo González Leandri quien vincula las objeciones hechas al normalismo por sus miembros más encumbrados con la escasa profesionalización del campo docente (González Leandri, 2001; Lionetti, 2007).

El presente estudio profundiza en algunas de las cuestiones allí formuladas a fin de mostrar cómo la figura de la maestra y el maestro normal se construyó en la Argentina como ocupación profesional en el telón de fondo de una serie de discursos sumamente críticos que impugnaban la formación normalista. Si bien estos discursos no afectaron la difusión del normalismo -escuelas y estudiantes aumentaron en esos años- sí alimentaron la desjerarquización de la actividad docente y permiten conjeturar la presencia de un núcleo duro y persistente en el tiempo en las representaciones del docente de escuela primaria en Argentina:

5 Para un resumen reciente de esta bibliografía ver Rodríguez y Soprano (2018: 9-67).

6 Sobre los orígenes ideológicos y los modelos de la escuela normal ver Carli (1995); Lionetti (2007); Alliaud; (2007) y Tedesco (2009).

7 Sobre las fundaciones de escuelas ver Fiorucci (2014, 2015), Rodríguez (2019), para análisis más acotados a contextos locales ver entre otros Lanzillota (2012), Billorou (2016). 
la idea que este no está preparado para su tarea. El ciclo temporal escogido (de 1884 a 1920) está definido por dos preocupaciones estatales antagónicas que trazan un ciclo con límites precisos. En un primer momento el Estado estaba compelido por la escasez de maestros diplomados y en consecuencia abocado a diseñar políticas para producir maestros. Luego, al final del período estudiado, esa inquietud fue reemplazada por su opuesta: el excesivo número de egresados de las escuelas normales que superaban en gran parte del territorio nacional los cargos disponibles en las escuelas primarias. Dado que el tema del normalismo convocó a actores sociales disímiles se privilegiará aquí un abordaje temático en lugar de concentrarse solo en lo dicho por algunas figuras o a lo discutido en determinados ámbitos o medios.

\section{Las críticas}

Para entender en el contexto en que se insertan estas visiones negativas es preciso dar cuenta de algunos datos materiales sobre la difusión del normalismo en la Argentina. La creación del Consejo Nacional de Educación en 1881 y la sanción de la ley 1420 en 1884 abrieron el camino hacia la institucionalización de un sistema público de educación con rasgos centralizados que derivó, entre otras cosas, en la creación de establecimientos de instrucción primaria. Si en los albores de la institucionalización del sistema de educación pública (en 1889) había en Argentina 2.263 escuelas públicas, un cuarto de siglo después, en 1915, el número de estas había aumentado más de tres veces sumando $7595 .{ }^{8}$ La ley 1420 era taxativa al respecto de que eran los maestros normales quienes debían estar a cargo de la enseñanza primaria. El Estado respondió a la demanda de maestros que el crecimiento del sistema público implicaba y que la legislación ordenaba creando escuelas normales en distintos lugares del país. Los estudios magisteriales se seguían luego de terminados los estudios primarios y estaban regidos por un programa de cobertura nacional que, como veremos más adelante, sufrió modificaciones en el período. Los alumnos debían cursar alrededor de una decena de materias por año, las cuales cambiaban a lo largo de la formación. Entre las asignaturas impartidas estaba la enseñanza de la pedagogía, la historia, las matemáticas, el idioma nacional y el extranjero, los ejercicios físicos y las labores manuales. El sistema preveía la posibilidad de obtener un título intermedio luego de dos años (subpreceptor) y uno de mayor jerarquía y especialización, el de profesor, luego de cinco años. El título de maestro y preceptor habilitaba para la instrucción primaria, y el de profesor para enseñar en escuelas normales. Los centros de educación magisteriales contaban con una escuela anexa identificada como de aplicación en donde los futuros maestros se ejercitaban en la tarea de enseñar.

En el término de unas pocas décadas, el Estado produjo gran cantidad de maestros, aún así, en algunas regiones siguieron faltando docentes diplomados por muchos años más. Entre 1906 y 1915 el número de egresados de la escuela normal pasó de 
656 a 1637 por año. ${ }^{9}$ En este contexto de expansión se generó una intensa discusión sobre el normalismo. Esta convocó a distintos tipos de figuras intelectuales con diversos grados de involucramiento en el área de la educación pública, entre los que se pueden identificar funcionarios de la burocracia educativa y agentes implicados en la gestión de las escuelas como los inspectores y los directores, los profesores y estudiantes de las escuelas normales, pero también intelectuales y escritores. Dentro de estos sobresale la voz de los inspectores quienes fueron una figura clave en la organización del sistema escolar. A principios del siglo XX se definió una estructura de inspección nacional especializada con agentes para los distintos niveles de educación (primaria y secundaria) y las distintas jurisdicciones. La inspección de las escuelas normales quedó conformada en 1903 pero ya antes de esa fecha había funcionarios que realizaban la tarea en ese ámbito. Los inspectores eran en general maestros y/o profesores normales a los que se les asignaban primordialmente quehaceres asociados a la tarea de vigilar e informar: es decir debían corroborar que la educación se dictase atendiendo a las disposiciones vigentes y comunicar del resultado de sus visitas periódicamente. ${ }^{10}$ En la práctica ostentaron un poder más amplio de aquel que le adjudicaba la normativa que regulaba sus funciones. Sus escritos fueron publicados en la prensa especializada y representaron un insumo importante a la hora de discutir la política educativa. Se asumía además que tenían un conocimiento de carácter científico, pero a la vez práctico, al estar en las inspecciones en contacto directo con escuelas y maestros. Al mismo tiempo, estos tenían el poder de echar a profesores y directores.

Entre los intelectuales, la mayoría de los que participaron en el debate sobre el normalismo ocupaban o habían ocupado funciones en la administración educativa como era, por ejemplo, los casos de Víctor Mercante, Manuel Gálvez y Leopoldo Lugones. Fue en la prensa educativa y en los documentos de la burocracia educativa (informes, censos, folletos) donde el debate sobre el normalismo tuvo mayor resonancia y serán por ello mismo foco de este trabajo. No obstante, como se podrá ver, el tema también fue abordado por la prensa periódica y en libros, formando parte del debate público más amplio. Fue una discusión intermitente, activada a veces por cuestiones coyunturales, que se entroncaba como iremos viendo con otros tópicos del momento, pero nunca dejó en todos esos años de expansión del normalismo de ocupar un lugar en la agenda pública.

Es necesario comprender que hubo impugnaciones de diversa índole al normalismo: algunas concretas y recortadas, como pueden ser las que tenían que ver con el funcionamiento cotidiano de las escuelas normales, por ejemplo el horario, y otras más fundamentales, relacionadas con los principios sobre los que se asentaba las políticas estatales en torno a este capítulo. En este trabajo nos concentraremos en las críticas fundamentales, aquellos temas que según los contemporáneos comprometían el éxito del proyecto educativo. Los reproches se referían tanto a las escuelas normales como a los maestros y las maestras normales. Es decir que cuando se criticaba al normalismo se censuraba tanto a la figura del maestro y

9 El Monitor de la Educación Común, año 35, n. 531, Buenos Aires 31 marzo de 1917, tomo 60, p. 160. 
la maestra normal como a los mecanismos que se usaban para formarlos y para distribuir las escuelas en el país. Las principales impugnaciones se pueden dividir para darle mayor claridad a la argumentación en tres grandes núcleos de temas, aunque debe quedar claro que estas se solapaban y superponían. Estas fueron: la influencia de la política en las escuelas normales; la formación que se impartía en esos establecimientos y la feminización del magisterio. ${ }^{11}$

\section{La política en el normalismo}

Con respecto a la influencia de la política en el mecanismo que formaba maestros, el tema tenía varias aristas entre las que se destacan dos cuestiones: el nombramiento de profesores en las escuelas normales y la política de fundaciones e ingreso. ${ }^{12}$ En los establecimientos normales los profesores eran elegidos según el sistema de cátedra y se estipulaba que quienes debían impartir la enseñanza en estos debían poseer el título de profesor normal. Según lo denunciado por diversos comentaristas, el favoritismo político hacía que los puestos no fuesen distribuidos a aquellas figuras con títulos específicos y además se permitía la acumulación de cátedras con otros cargos públicos. La preocupación por este tema -que también incumbía a lo que sucedía con los colegios nacionales- apareció temprano. En 1899 ya se puede observar esta inquietud en las justificaciones de un controvertido intento de reformar el sistema educativo. En un contexto de agrias discusiones económicas por el déficit fiscal durante la presidencia de Roca, el ministro de Instrucción Pública (Osvaldo Magnasco) ordenó cerrar por decreto varias escuelas normales y colegios nacionales en las provincias, reemplazarlos por institutos de enseñanza práctica (industriales y escuelas agrícolas) y cancelar las becas. ${ }^{13} \mathrm{La}$ medida se sustentaba, entre otras cosas, en la necesidad de evitar que el magisterio fuese víctima de ese "albur de las influencias y recomendaciones que no siempre llevan a los mejores y más aptos a desempeñar los cargos educativos más delicados y difíciles". El plan fue ampliamente resistido y finalmente abolido en el recinto legislativo. ${ }^{14}$ Unos pocos años más tarde, en 1906, ya es posible hallar este tópico en la prensa educativa. Este figura en el primer número de la revista que en ese entonces se planteaba como la vanguardia del debate educativo en el país: Archivos de Pedagogía y Ciencias Afines de la Universidad de La Plata dirigida por el pedagogo Víctor Mercante. Allí, Mercante, quien había sido director de una escuela normal y desde 1906 presidía la sección Pedagógica de la Universidad de La Plata que luego se transformaría en la primera facultad de Ciencias de la

11 Otro tema importante fue el motivo económico, en particular el salario y el financiamiento de las escuelas. Ver Fiorucci (2019).

12 Había otra dimensión de la influencia de la política que era la participación de directores, profesores y alumnos de las escuelas normales en las reyertas políticas locales haciendo de las escuelas normales escenarios de conflictos ajenos a lo educativo. Ver Lionetti (2007).

13 La refundación de las escuelas normales (3 de febrero de 1900: 5).

14 El plan pretendía que los colegios nacionales absorbieran la educación normal y también preveía la transformación de algunos colegios nacionales en escuelas de tipo práctico que debían ser sostenidas por las provincias. Según la literatura, este buscaba restringir el acceso a la universidad de algunos sectores y diferenciar la educación secundaria. Lionetti (2007: 72-79) y Tedesco (2009:159-175). 
Educación y el en su primer rector, realizaba un elaborado informe sobre los problemas educativos que aquejaban a la instrucción nacional. ${ }^{15}$ En un apartado que titulaba "nombramientos" se preguntaba cómo había entrado el mal elemento a las escuelas normales y a los colegios nacionales y sostenía que había sido a través de "la influencia, la recomendación, la tarjeta, la política". Mercante afirmaba que los ministros que se resistían a las presiones en los nombramientos terminaban renunciando. Con tono sombrío concluía que por ese camino llegaba a la escuela normal "el descalificado, el que sabía que no tenía méritos", lo cual abrevaba en un clima que calificaba de "postración moral del magisterio" (Mercante, 1906: 178). Es decir que en la mirada de Mercante las escuelas donde se formaban los maestros no ofrecían una buena educación porque "la política" abría sus aulas a malos profesores.

La influencia de la política en el normalismo fue parte de los cuestionamientos de Leopoldo Lugones. Como se sabe, Lugones ocupaba en la primera década del siglo XX un lugar destacado en la galería de escritores argentinos y era una figura pública de relativa resonancia. ${ }^{16}$ A la par de su labor literaria se desempeñó como visitador general de enseñanza entre 1900 y 1903 y, en 1904, asumió como inspector general de enseñanza secundaria y normal, cargo que ocupó hasta 1915 cuando se hizo cargo de la Biblioteca de Maestros. Lugones colaboró recurrentemente en las páginas del Monitor de la Educación Común. En 1909 apareció en esa revista seriada su obra Didáctica. Allí vertió sus apreciaciones sobre el estado de la educación nacional y realizó una de las críticas más elaboradas al normalismo que iremos retomando a lo largo del trabajo. ${ }^{17} \mathrm{El}$ escritor consideró que "sería injusto culpar [de los problemas de la educación] a los maestros". "En esto, como en todo, [afirma] hay que apreciar el árbol por sus frutos. Caiga el baldón sobre los que formaron a esos maestros, y remédiese el daño atacándolo en su raíz". Lugones sostuvo que la calidad de los profesores en las instituciones normalistas se veía comprometida porque había "muchos más abogados y médicos que individuos de profesión” cuya influencia tenía para el escritor efectos "deplorables” (Lugones, 1910). La apreciación de Lugones se comprende mejor si se entiende que era un lugar común la percepción que la docencia (en especial el profesorado secundario) debía ser una profesión que se ejerciera en forma exclusiva (Bunge, 1909: 437).

En relación con el profesorado normalista, Lugones advirtió sobre las consecuencias de la "cátedra como complemento de la renta o del sueldo personal" lo que atraía "al advenedizo sin escrúpulos" (Lugones, 1910). El origen último de esta situación se relacionaba también para Lugones con la política. Por esto proponía que las escuelas normales dejaran de estar bajo la órbita del ministerio, fueran gestionadas por el CNE y sus cátedras reservadas para los profesores normales. "Si hay algo justo y evidente -afirmó Lugones- es que las cátedras de las escuelas normales sean para los profesores normales” (Lugones, 1910). Es preciso aclarar,

15 En el artículo se hacía eco del informe producido por el inspector de enseñanza secundaria Santiago Fitz Simon quien concluía que el nivel de los alumnos que ingresaban a la escuela secundaria era malo.

16 En 1903 fue escogido por una encuesta realizada por la revista El Gladiador como la voz literaria del momento desplazando a figuras destacadas de la generación del ochenta.

17 Sobre Didáctica de Lugones ver Dussel (1997). 
para que se entienda mejor la sugerencia, que el CNE gozaba de autonomía financiera y administrativa. Esta autonomía reposaba en que sus fondos no dependían de las partidas del Poder Ejecutivo o del Ministerio, sino que eran parte de un fondo específico provenientes de impuestos municipales y nacionales. ${ }^{18}$

El tema de la distribución de las cátedras en las escuelas normales por favores políticos, ajenas a consideraciones del orden de lo educativo, fue un tema también central en la novela de Gálvez. Este señaló, al igual que Lugones, que en los claustros de las escuelas normales abundaban los abogados, los médicos además de las esposas e hijos de los políticos en detrimento de los profesores normales.

Cada cátedra, es, lógicamente, una fortaleza que, antes de ser tomada, ha promovido formidables batallas. Los políticos de la provincia que, por sus cargos, tienen influencia en Buenos Aires combaten heroicamente para hacerlas dar a sus amigos; son las mejores posiciones en las repartijas de la política. Todos los "intelectuales" poseen cátedras; en caso contrario, esperan obtenerlas apenas haya un cambio de gobierno. (Gálvez, 1914: 101).

El tema del nombramiento espurio también fue mencionado en los informes sobre el estado de la enseñanza normal. Ernesto Bavio, inspector de escuelas normales, denunció en 1911 los efectos de la política sobre el estado de la educación normal y se refirió específicamente al nombramiento, describiendo a "los políticos" como "esa fuerza ciega de efectos desastrosos". En 1916, el documento que reunió los informes de los inspectores normales también retomó el asunto argumentando que el problema de la escuela normal "era una cuestión de profesorado" y que las "fallas... en la enseñanza normalista [se debían a la presencia] de elementos extraños, no solo a la docencia de carrera, sino a la aplicación seria de la enseñanza, que se toma como es sabido, como ocupación transitoria”. Por esto se concluía que los "profesores sin título alguno y despojados de autoridad para orientar a la juventud deben ser desechados de las escuelas" (Ministerio Justicia e Instrucción Pública. Departamento De Instrucción Pública, 1916).

Según la literatura, la denominada "empleomanía" -"el uso del empleo público como recompensa por el apoyo político"- fue una práctica característica del período: tanto los gobiernos conservadores desde 1880 y los gobiernos radicales a partir de 1916 apelaron a este recurso. ${ }^{19}$ Distintas voces la denunciaron como un vicio que afectaba a la calidad institucional y administrativa de la república. ${ }^{20}$

18 González Leandri afirma que el presidente del CNE tenía rango de ministro y en general gozaba de relativa autonomía. Martín Castro sostiene que, por el contrario, aunque el CNE contaba entre su personal con figuras con trayectoria en el campo educativo también incluía a figuras "más cercanas al perfil del político profesional [...] por lo que el CNE no parecía diferenciarse en demasía de otras áreas de la estructura administrativa estatal en las cuales el gobierno central o los gobernadores, disfrutaban de una considerable libertad a la hora de nombrar amigos políticos como forma de construir máquinas políticas o de premiar la participación valiosa de aliados en los procesos electorales". Castro, M (2010). González Leandri (2001: 513-535).

19 La bibliografía sobre este tema es amplia. Una lectura reciente que hace foco sobre la administración educativa y de la salud es el texto de Ricardo Salvatore. Salvatore (2016).

20 En diciembre del mismo año en que se publicaba La Maestra Normal, en 1914, el diputado socialista Juan B. Justo se refería a la distribución de las cátedras en las escuelas normales preocupado no tanto por la calidad de la educación sino por el alto costo de la educación secundaria en el país afirmando que éste 
Las intervenciones antes citadas nos permiten concluir que la empleomanía era vista también como un problema específico del normalismo que afectaba la eficacia de la educación en el país y socavaba, por lo tanto, la legitimidad de una de las apuestas más fuertes del proyecto liberal reformista: la educación pública. Es preciso anotar que estas críticas soslayaban un aspecto importante: no existían en el país suficientes profesores normales para cubrir las cátedras, lo que hacía que la empleomanía fuera a la vez un problema, pero también una solución (Dussel, 1997: 54). Según estadísticas oficiales entre 1906 y 1915 se habían recibido solo 563 profesores, cifra que no alcanzaba para cubrir los puestos existentes. ${ }^{21}$

Otra dimensión del problema de la política era para varios comentaristas de la época la fundación de escuelas normales sin un plan racional. ${ }^{22} \mathrm{El}$ patrón de apertura de escuelas normales respondió solo en los primeros años a una planificación a escala nacional a través de la ley que estipulaba la apertura de escuelas normales en las capitales de provincia. Luego, la creación de escuelas normales fue el resultado de negociaciones y redes clientelares entre los políticos locales, determinados sectores de la sociedad y las dirigencias nacionales. Lucía Lionetti dice al respecto que "con poca información y víctima de juegos ajenos a lo educativo, los ministros atendían reclamos de políticos locales que solicitaban una nueva fundación de instituciones normalistas para proporcionar trabajo a las personas que resultaran favorecidas por los puestos" (Lionetti, 2007: 167179). Por ejemplo, en el caso de la Escuela Normal de Posadas, según las fuentes recogidas por Teresa Laura Artieda, los "gestores de la institución fueron los docentes primarios de Misiones" (Artieda, 1993: 171). Otros testimonios subrayan para el mismo caso las gestiones del inspector de Territorios Nacionales Raúl B. Díaz, quien convencido que los maestros debían ser del lugar donde dictaban clases solicitó a las autoridades nacionales una escuela normal para Posadas, junto con otra para Santa Rosa de Toay (Fiorucci, 2018). Un folleto editado por la Escuela Normal de San Fernando señala su apertura en 1912 como el producto del pedido de un diario local (El Pueblo) cuya dirección en manos "de un antiguo vecino, diestro conocedor de los verdaderos intereses de la región, el señor Augusto Favier, la sostuvo con todo entusiasmo hasta que ella fue una realidad" (Rossi, 1937:3). ${ }^{23}$ Según el folleto mencionado, la iniciativa mereció primero el respaldo de los vecinos y luego de la prensa de la Capital.

Se precisa más información para comprender cómo los reclamos convergían en la apertura de una escuela. En otras palabras, no se sabe cuáles eran las negociaciones y recursos que debían movilizarse para obtener una escuela normal en la localidad. En las últimas dos décadas la historiografía ha avanzado en el análisis de la construcción estatal bajo el orden conservador dando cuenta de una escena

se debía a la multiplicación de cátedras a cambio de favores personales. Salvatore (2016).

21 En ese mismo período se habían recibido 8768 maestros normales. Ver estadística general de la enseñanza primaria en Argentina (31 de marzo de 1915).

22 Con otras particularidades, el sistema de nombramiento de los maestros en las escuelas elementales tampoco fue ajeno al denominado problema de la "empleomanía".

23 Supuestamente su pedido estaba motivado por un interés personal: una de sus hijas debía trasladarse todos los días a Buenos Aires para poder estudiar en la escuela normal. 
muy compleja de interacciones en lo que se refiere a las relaciones entre los gobiernos nacionales y locales (ya sea provinciales y/o territorianos) y la sociedad civil y sus dirigentes (Castro, 2017: 89-112). El tema escapa a los fines de este trabajo, no obstante, se puede afirmar que la supuesta centralización del sistema educativo enfatizada por la historiografía como un rasgo saliente de este último- encontró en este aspecto del proyecto normalista un límite concreto. A partir de fines del siglo XIX el patrón de fundación de escuelas normales no se decidió (al menos exclusivamente) en Buenos Aires, ni respondió solo a los intereses del gobierno nacional. La falta de previsión en la fundación de algunas escuelas se evidencia en la palabra de los directores de las escuelas normales quienes advertían en sus informes anuales al ministro de Justicia e Instrucción Pública las carencias de algunas fundaciones (Fiorucci, 2014). Es probable que haya sido Lugones en su obra Didáctica en 1909 quien más tempranamente haya prevenido que estos problemas se explicaban por la ausencia de un plan. Lugones sostenía que las escuelas se debían fundar de acuerdo con un estudio que determinara las necesidades, pero advertía en cambio que los "políticos locales trabajan la nueva fundación con el objeto regularmente plausible de proporcionar trabajo a quince o veinte personas que resultarán favorecidas por los puestos". "Esas veinte necesidades satisfechas” concluyó Lugones "perjudican a toda la enseñanza” (Lugones, 1909a).

En 1911 el inspector Ernesto Bavio denunció que se fundaban escuelas normales en centros "que no están preparados para su mantenimiento y difusión". Se pide una escuela normal -afirmó Bavio- como "se pide la construcción de un puente" y esto llevaba a una "existencia precaria" (La instrucción primaria en 1911, 1912). En 1916, los inspectores de escuelas normales en su conjunto volvieron sobre este asunto advirtiendo que el problema generaba excedente de maestros en algunos lugares, lo que en el lenguaje de la época era identificado como el problema del "proletariado normalista" (Inspección general de Enseñanza Secundaria Normal y Especial 1916: 19). El inspector Celso Latorre concluyó en ese escrito que la distribución de las escuelas era "inconsulta" ya que no "obedec[ía] a un criterio superior de gobierno”. El panorama se empeoraba en la visión de los inspectores por la apertura de las escuelas incorporadas: establecimientos privados (en general católicos) donde se impartía la enseñanza para el magisterio. Los inspectores se oponían a este tipo de establecimientos porque consideraban que agravaban el exceso de maestros y volvían más trabajosa la tarea de la inspección, ya superada en sus capacidades. ${ }^{24}$ Además, al igual que Lugones, quien las había descripto como un "subterfugio confesional contra el laicismo", ${ }^{25}$ los inspectores rechazaban su carácter confesional "en pugna con el laicismo absoluto de la educación primaria argentina” (Memoria del Ministerio de Justicia e Instrucción Pública, 1916: 32).

Pese a los juicios alarmistas sobre la cantidad de escuelas, el Estado continuó abriendo establecimientos normalistas. Entre 1917 y 1920 se fundaron 13 escuelas. El afán igualitarista, entendido como la ausencia de barreras para acceder a la

24 En 1916 hay tres inspectores técnicos para la oficina de Inspección General de Enseñanza Secundaria Normal y Especial. En 1916 según estadísticas oficiales hay 71 escuelas normales en funcionamiento a las que concurren 37.738 alumnos.

25 Lugones (1910a: 776). 
formación normalista, junto con los intereses políticos que se tejían en torno a las fundaciones, primaron sobre criterios de otro orden, como el de una planificación ordenada de las escuelas. Por otro lado, es preciso notar que los argumentos negativos en torno a la abundancia de establecimientos de enseñanza para el magisterio convivían con otros que subrayaban la necesidad de continuar con la política de apertura de escuelas normales. Por ejemplo, el estudio previo al presupuesto educativo de 1913 realizado por el vocal del CNE Delfín Jijena, a la vez que anunciaba nuevas fundaciones, señalaba que dada la escasez de maestros para las escuelas primarias "hacían falta muchas escuelas normales más", sin mencionar limitaciones referidas a su ubicación. ${ }^{26} \mathrm{El}$ tema se relacionaba con otro tópico que fue señalado como una dificultad de las escuelas normales: el excesivo número de alumnos en las aulas.

La formación magisterial demandaba, además de la adquisición de conocimientos, una enseñanza de índole práctica y, por lo tanto, los maestros debían ejercitar la docencia en las escuelas anexas. Se creía que para instrumentar esta experiencia los cursos no debían ser demasiado numerosos (Berra, 1901: 15). Si uno lee atentamente los informes de los directores de las escuelas normales podrá constatar que, junto con la difusión de las escuelas, crecía también el alumnado de las ya instaladas, revelando que pese a las críticas que se le pudieran hacer la popularidad del normalismo no disminuía. ${ }^{27}$ En 1905 el inspector de escuelas normales afirmaba que en la Capital, esos establecimientos "atestados de alumnas, [no podían] llenar su objeto en lo relativo a la práctica pedagógica” (Inspección General de Enseñanza Secundaria y Normal, 1904: 138). Lugones observó en Didáctica que debido su crecimiento se asistía "a la escuela monstruo, sin práctica efectiva” (Lugones, 1909a: 337). En 1910, Lugones participó del armado de un nuevo reglamento para las escuelas normales donde se establecieron una serie de medidas tendientes a restringir el ingreso. Allí se introdujeron límites al número de divisiones por escuela además de confinar el acceso a la escuela normal solo a aquellos que habían cursado sus estudios primarios en escuelas de aplicación. ${ }^{28}$ En 1915, se modificó el reglamento nuevamente y se fijó en 40 el límite de alumnos por aula. ${ }^{29}$ Estas restricciones no se pudieron sostener primando la voluntad estatal de dar acceso sin restricciones a este tipo de educación. En los informes de los inspectores de escuelas normales de 1916 se reclamaba enfáticamente que se pusieran en práctica estas regulaciones y que se limitaran las admisiones. El inspector Gauna observó al respecto que las escuelas normales eran "establecimientos de enseñanza profesional en los que el Estado no [tenía] la obligación de proporcionar todos los asientos que se le pid[ieran]". ${ }^{30}$ Las intervenciones referidas al excesivo número de alumnos en las escuelas muestran cómo distintos actores involucrados en la gestión de las escuelas alertaron e intentaron frenar

26 Jijena (1912)

27 Cabe aclarar que este tema fue también motivo de alarde entre algunos directores quienes se congratulaban del número de aspirantes. Ver por ejemplo Memoria Presentada al Congreso Nacional de por el ministro de Justicia e Instrucción Pública (1904).

28 Decreto orgánico Escuelas Normales - 17 de mayo de 1911 (30 de junio de 1915: 9).

29 El Monitor de la Educación Común (30 de junio de 1915)

30 Memoria del Ministerio de Justicia e Instrucción Pública Departamento de Instrucción Pública (1916: 20). 
el afán inclusivo del proyecto. Los directores de escuela también fueron parte del elenco de voces que se opusieron al crecimiento sin control de las escuelas. Por ejemplo, el director de la escuela $\mathrm{N}^{\circ} 8$ de la Capital Federal exhortó a las autoridades en 1916 a "poner un dique a la ola cada vez mayor y más imperiosa de los aspirantes a ingreso a las escuelas normales de esta Capital” (Paz, 1916: 141).

\section{Formación}

La pregunta por el tipo de formación que se debía impartir a los maestros es un interrogante que recorre la historia del normalismo en la Argentina. En los años de su primera expansión este tema convocó a figuras diversas y motivó recurrentes cambios en los planes de estudio. Desde temprano distintas voces expresaron sus reparos frente al contenido de la enseñanza que se impartía en esos establecimientos y la asociaron a mala calidad de los maestros. De las intervenciones sobre este asunto se deduce que uno de los mayores desafíos para las autoridades a la hora de diseñar el currículo de las escuelas normales fue la articulación entre la enseñanza de los conocimientos de tipo general con los profesionales, teniendo en cuenta además que los alumnos llegaban con una preparación que era juzgada como insuficiente. Un artículo reproducido por el Monitor de la Educación Común en el primer año del siglo resumió el problema afirmando que en las escuelas normales se enseñaba "mucho menos de lo que se debiera [...] pues la masa de conocimientos que se han de enseñar es tan grande, que absorben completamente el tiempo de escuela y dejan reducido lo esencial, que es la formación del maestro a una mínima parte” (El arte de enseñar, 1900). Se subrayaba además como un problema la desconexión entre los contenidos aprendidos en la escuela normal con la tarea que esperaba a los futuros maestros. Decía Francisco Berra en 1900 que "lo usual entre nosotros es que la enseñanza de las escuelas normales ande por un lado y que la enseñanza de las escuelas ande por otro" (Berra, 1901: 14). En consonancia con estos argumentos es posible observar que los pedidos de reforma apuntaban en general a modificar la relación entre la enseñanza de contenidos, la pedagogía y la práctica en el aula. En 1906, Pizzurno justificaba la necesidad de reformar el currículo afirmando que "el plan de enseñanza se halla[ba] excesivamente recargado en relación al tiempo del que disponen los alumnos maestros para estudiar todos los ramos que comprende y a que el hecho de tener que adquirir simultáneamente conocimiento sobre todas las materias generales, conocimientos pedagógicos teóricos, habilidades de orden físico y manual y aptitudes profesionales prácticas mediante el ejercicio continuo, efectuado en la escuela de aplicación" (Pizzurno, 1906). Poco después, en 1911, el artículo que anunciaba la preparación de un nuevo plan de estudios afirmaba que el éxito de la escuela normal estaba atado a la suerte de la escuela anexa, allí donde los maestros debían realizar sus prácticas.

Los juicios negativos sobre los planes de estudios tuvieron efectos concretos. Entre 1884 y 1920 se modificaron al menos cinco veces los de planes de estudio de las escuelas normales. Primero en 1886, cuando se alteró el plan introducido en 1876. Un año después, en 1887, se implantó un nuevo programa que aspiraba 
a regir para todas las escuelas. Este último se volvió a modificar en 1904 con un plan que también ansiaba imponerse en todos los establecimientos y que se justificaba oficialmente en la necesidad de "destruir la anarquía reinante, e imprimir sencillez, claridad y eficacia al régimen de los colegios nacionales y escuelas normales que, por aquellas causas, combinadas con otras de la misma índole, han caído en una decadencia que a toda costa conviene detener." (Plan de estudios de los colegios nacionales y escuelas normales, 1904: 545). Según registros oficiales, entre 1900 y 1904 se encontraban en vigencia 4 programas en simultáneo (Anexos de Instrucción Pública, 1904). En 1910 se introdujo, además, un plan de estudios para escuelas normales rurales que preveía una formación más acotada en el tiempo. En 1914 se alteró el plan de estudios que regía para las escuelas normales y en 1916 este se volvió a modificar en el contexto de la reforma promovida por Saavedra Lamas y diseñada por Víctor Mercante. Esta reforma que tuvo una vida muy corta -fue derogada una año después de ser implementada- reducía la escolaridad primaria a 4 años, introducía una escuela intermedia y suponía una reforma integral de la educación secundaria. ${ }^{31}$ Si observamos el despliegue de estos planes, los aspectos que se alteraron con mayor recurrencia fueron la duración de la formación y, por ende, la cantidad de materias; el lugar otorgado a la pedagogía en el currículo y el tiempo dedicado a la práctica docente en la escuela anexa. Según un estudio que antecedía el Censo Educativo de 1909 "la continua experimentación con los planes de estudio en las escuelas normales" eran producto de "ideas inseguras y no maduradas" (Latzina, 1909: 14). Claramente la inestabilidad en los planes era un síntoma de los cuestionamientos que recibía ese tipo de instrucción. ${ }^{32}$ Incluso algunos de los directores de las escuelas normales también identificaron en el "cambio frecuente de programas" y planes un problema "para el éxito en la enseñanza" (Vera, 1902: 492). Aquí es preciso acotar que la inestabilidad en la enseñanza se condice con un área de la gestión pública caracterizada por el cambio recurrente de autoridades (Rodríguez, 2019:227-232).

Los juicios negativos sobre la instrucción que se impartía en la escuela normal no deben confundirse con un reclamo por una educación más rigurosa en términos académicos. La política de educar maestros en escuelas normales se basaba en la visión que era más importante la formación para la profesión que la adquisición de conocimientos académicos. Es decir que predominaba una perspectiva que postulaba que las escuelas normales debían proveer una formación acotada que hiciera de la práctica de la docencia el eje de la enseñanza asimilando el magisterio al aprendizaje de un oficio. Este punto se mezclaba con una visión de que el maestro debía ser una figura de gustos sencillos, capaz de adaptarse a los medios en que le tocara actuar. Sarmiento había resumido este argumento tempranamente en su obra Educación Popular. Allí presentaba sus apreciaciones admiradas sobre la escuela normal de Versalles y señalaba que "la educación que ahí reciben [los alumnos] se contrae especialmente a conservar entre ellos los gustos más simples, las aspiraciones más limitadas y la humildad que podría

31 Este último plan estuvo en práctica por un período más largo, hasta 1941.

32 Los problemas en la formación también involucraban a los profesores normales dado que el profesorado era una continuación de la enseñanza normal. Ver Bunge (1909: 386). 
llamarse con propiedad aldeana" para que estos se adaptaran a vivir "en una noble y afanosa mediocridad" (Sarmiento, 1849: 146). En tono similar se expresaba, en 1916, el escritor nacionalista Matías Sánchez Sorondo, quien en ese momento se desempeñaba como director de escuelas de la Provincia de Buenos Aires. Este argumentaba que el "país necesitaba al maestro modesto; sin títulos de suficiencia tanta que deslumbre y esterilicen en la espera; el maestro que cumpla en su tarea diaria, cultivando con amor el rincón del jardín humano que la suerte le dejará" (Sánchez Sorondo, 1916: 58). Rosario Vera Peñaloza -una figura involucrada en el día a día del normalismo (era directora de una escuela normal)- instaba a las alumnas maestras a no perseguir vocaciones científicas. Aunque "la ciencia os atraiga (afirmaba Vera Peñaloza) dejad que intenten el ascenso a la difícil montaña los que buscan otras especulaciones, vuestro sitio, ya os lo he dicho, está en el valle, sois las sembradoras y basta para la germinación de la semilla" (Vera Peñaloza, 1915: 493).

Pese a la preeminencia de posiciones como las citadas, es posible observar que la prensa educativa local se interesó muy tempranamente por un proceso que se estaba dando en otros contextos nacionales: el pasaje de la formación magisterial de las escuelas normales a las universidades. En Estados Unidos, modelo sobre el que se había asentado el normalismo argentino, desde finales del siglo XIX la educación de los maestros comenzó a realizarse progresivamente en universidades. Según la literatura, esta conversión se dio de dos formas: por un lado, las escuelas normales se tornaron teachers colleges (entre 1911 y 1930 hubo 88 de estas conversiones) y, al mismo tiempo, las universidades abrieron sus puertas a la formación para docentes incorporando programas de pedagogía y educación (Labaree, 2008; Ogren, 2005: 201). De distintas formas en Alemania, Inglaterra y Suiza también comenzaban a abrirse los estudios universitarios a la formación de maestros. Claramente el movimiento implicaba, aunque con diferencias según el caso, una profesionalización de la ocupación. La universidad proveía de estatus y credenciales académicas y la formación dejaba de ser secundaria. Se creía además que al volverse un título universitario la docencia atraería a un mayor número de varones lo que también mejoraría el prestigio de la ocupación (Anderson, 2015: 15).

El Monitor de la Educación Común informó de este proceso en varias notas. Por ejemplo, en 1910 se transcribieron las conclusiones del Congreso Internacional de Enseñanza Primaria celebrado en Francia. En estas se afirmaba la necesidad de que los maestros reforzaran su educación cursando dos de los cuatros años de su formación en las universidades (Congreso Internacional de Enseñanza Primaria, 1910). En 1912 la revista tradujo un extenso artículo titulado "La Preparación profesional de los maestros en Universidades” escrito por el director del Museo Pedagógico de París Victor Henry Friedel (Friedel, 1912). Allí Friedel describió y sopesó los ensayos hechos por distintos países en relación con esta materia y, si bien no se inclinó enfáticamente por la formación universitaria, destacó los beneficios que traía el acceso a la universidad para los maestros, sobre todo en relación con el conocimiento de la pedagogía. Unos años después El Monitor de la Educación Común tradujo el texto "El maestro y la universidad" del profesor francés Henry Goy. En este, además de ofrecer un panorama sobre el asunto, Goy 
deja ver su admiración por el sistema americano que en su visión ha logrado combinar la formación profesional con la enseñanza científica. La nota finaliza afirmando que "a pesar de la insuficiencia de su personal de enseñanza actual, los Estados Unidos nos ofrecen un ejemplo digno de ser meditado: una escuela de educación de carácter universitario, de método científico, donde va a preparase un cuerpo de enseñanza homogéneo, democrático y nacional” (Goy, 1919).

La inquietud por hacer de la educación un saber científico no fue completamente ajena a la escena argentina en el período. En 1896 se inauguró una cátedra en la Universidad de Buenos Aires de Ciencias de la Educación y luego, en 1905, se creó la Sección Pedagógica en la recién inaugurada Universidad Nacional de La Plata. Dicha Sección -animada por Mercante- derivó en la fundación en 1914 de una Facultad de Ciencias de la Educación y luego en la apertura de una nueva carrera de Pedagogía y Ciencias de la Educación. ${ }^{33}$ Hay que tener en cuenta, sin embargo, que estas inquietudes no convergían en aquello que el Monitor de la Educación Común observaba como una tendencia en otras regiones: la conversión en sede universitaria de la instrucción para los maestros, es decir la reforma del normalismo. Lo que se puede observar con las iniciativas antes mencionadas son los primeros estadios de la emergencia de un campo de saber orientado al estudio de los fenómenos educativos, pero no un proceso que apunte a la profesionalización de la docencia primaria. ${ }^{34}$ Incluso El Monitor de la Educación Común, aunque informó de lo que sucedía en otros contextos, no sugirió, ni siquiera discutió su pertinencia para el caso argentino.

\section{La feminización y sus críticos}

Al compás de la expansión del normalismo, también se acentuó su perfil femenino. Si apelamos a los datos del Consejo Nacional de Educación antes de la sanción de la ley 1420, la proporción entre varones y mujeres en la ocupación se repartía prácticamente igual pero esta ratio se fue modificando de forma muy progresiva. Según las estadísticas oficiales, en 1884 las mujeres constituían el 50\% del plantel docente, en 1900 estas sumaban el 72\% de los docentes de las escuelas de gestión estatal. La feminización de la docencia fue más temprana y marcada en las escuelas estatales y en las grandes ciudades. En la ciudad de Buenos Aires las mujeres representaban, en 1900, un 78\% del plantel docente primario, es decir un $6 \%$ más que en el promedio nacional y, en 1910, ya sumaban el $83 \%$ del plantel docente. ${ }^{35}$ Allí también las mujeres accedieron en mayor proporción a los cargos

33 Parte de este fenómeno de profesionalización se plasmó en la apertura de los profesorados en la Universidad de La Plata (1902) y en la Universidad de Buenos Aires (1907). Los profesorados supusieron la emergencia de un nuevo actor social: "el profesorado diplomado". Esto, sin embargo, no significó una profesionalización del docente primario. Pinkasz (1992).

34 Para un panorama de la emergencia del campo de las Ciencias de la Educación ver Suásnabar (2013; 2018: 4-23) y Southwell (2014: 1-32).

35 Si seguimos los datos de los Censos nacionales la cifra difiere porque esta retrata la actividad en su conjunto: es decir todos aquellos que declaraban dedicarse a la educación. Aun así, según el censo de 1895 había 10.063 maestros en Argentina. De esa cifra 6.157 eran mujeres, es decir alrededor de un $61 \%$. 
de directoras. De los 200 directores que había en la ciudad de Buenos Aires en 1910, 145 eran mujeres (Informe de Instrucción Pública, 1910). En los territorios más apartados la presencia de la mujer fue por el contrario menos pronunciada. En 1900 las mujeres constituían un 52\% del magisterio en las gobernaciones y en 1910 rozaban el 60\%. ${ }^{36}$ En las escuelas particulares en el año 1900, que es para cuando existen datos globales, las mujeres eran mayoría por un margen escaso (el 53\%).

La feminización del magisterio se dio dentro de un contexto de expansión del trabajo femenino en general. Los cálculos estiman que en las primeras décadas del siglo entre el $20 \%$ y el $30 \%$ de la fuerza laboral estaba constituida por mujeres (Queirolo, 2018). Las maestras constituían un porcentaje muy marginal de esa fuerza laboral. Según lo que se puede reconstruir del censo de 1895, solo un $1,55 \%$ del total de mujeres trabajadoras se dedicaban a la docencia. Probablemente esta cifra fuera mayor en 1914. No obstante, la presencia y visibilidad del magisterio como "profesión de mujer" superaba al peso real que las maestras tenían dentro de la fuerza laboral femenina total. Esta visibilidad estaba relacionada con el crecimiento del sistema educativo en todos sus niveles en una geografía muy amplia. El propio censo de 1914, aunque no ofrece datos precisos sobre el número de maestras, señalaba en sus comentarios a la docencia como uno de los principales espacios donde la mujer toma "parte en la vida económica" del país. ${ }^{37}$

En el caso del magisterio, la feminización fue el producto de una serie de cuestiones que -es preciso aclarar- se repitieron en los más variados contextos nacionales. En primer lugar, se puede decir que desde el discurso esta ocupación fue construida como femenina, lo que habilitó y legitimó la participación de las mujeres en el campo educativo. Por un lado, se consideraba que por sus cualidades intrínsecas las mujeres estaban mejor dotadas que los hombres para la tarea de enseñar. En las intervenciones de la época se resaltaban ciertas cualidades como la ternura, la paciencia y el apego a la tradición "consideradas naturales al género femenino y acordes con la tarea de enseñar” (Alliaud, 2007: 111). Por otro lado, según la teoría pedagógica decimonónica, la tarea de la maestra aparecía fuertemente asociada a la de la madre, por lo cual el magisterio se proyectaba como una ocupación adecuada para el género, pero también noble y decente. A estas consideraciones se sumaban razones materiales. A las mujeres se le podía pagar remuneraciones menores y por eso mismo supondrían un menor gasto para el Estado. Con esta iniciativa se pensaba que también se podría resolver en parte el problema de la integración de las mujeres pobres al mercado de trabajo. Otra vez fue Sarmiento quien tempranamente dejó asentado este capítulo del proyecto educativo en su obra Educación Popular. Enumerando todas estas razones y fiel a la idea de que las mujeres debían ser educadas igual que los varones, Sarmiento observó la "importancia moral y social de introducir a las mujeres

36 En 1895 la proporción de maestros varones era en las gobernaciones del 52\%. Informe presentado al Ministerio de Instrucción Pública por el Dr. José María Gutiérrez, tomo I (1896: 182) e Informe de Instrucción Pública (1910: 621).

37 La población de la república considerada según sus profesiones (1914: 253). La feminización de la carrera docente también se dio en la conformación del cuerpo de profesores de las escuelas normales, aunque a un paso más lento que en el cuerpo docente de las escuelas primarias. Pinkasz (1992). 
a la enseñanza pública" mientras que concluía que era a las mujeres a quienes "de derecho corresponde" la instrucción primaria (Sarmiento, 1849: 111-115). ${ }^{38}$ Como ha sido apuntado por la bibliografía, las mujeres se abocaron a la docencia porque la escuela normal les abrió la posibilidad de una educación, de un espacio que les otorgaba reconocimiento e influencia en la esfera pública y de un trabajo remunerado con relativa estabilidad y el goce posterior de una jubilación. ${ }^{39}$

El consenso frente a la feminización del magisterio no significó, sin embargo, la ausencia de cuestionamientos. Por el contrario, en el período aquí estudiado fueron muchas las voces que expresaron fuertes críticas al hecho de que la educación quedase en manos exclusivamente femeninas y se interrogaron sobre sus efectos. En la revista fundada por Víctor Mercante, Archivos de Pedagogía y Ciencias Afines, este fue un tema abordado en varias oportunidades. La mayoría de las voces que se refieren al tópico se oponen al carácter indiscriminado del proceso y abogan por ponerle coto, a la vez que demandan iniciativas para atraer al varón a la escuela normal. Víctor Mercante escribió en su revista uno de los primeros artículos al respecto. Allí celebró el ingreso de la mujer a la docencia y apelando a argumentos positivistas (por ejemplo, observando el tamaño del cerebro y la fuerza corporal) sostuvo que la inteligencia de la mujer no era inferior sino distinta. Por esto mismo, para Mercante estos debían ejercer trabajos diversos. Allí juzgó que la "limitada esfera elaborativa [de la mujer] acompañada de una disminución de la motricidad voluntaria" la preparaban para trabajos relacionados con "la imitación" como "la costura y el bordado", pero no para que aquellos que involucraran "la formación del carácter" que precisaban "un criterio amplio, una afectividad estable, una voluntad tesonera antepuestos en el hombre", pero no en las mujeres (Mercante, 1908: 379). Este argumento lo llevó a sostener que se debía limitar el trabajo de la mujer como maestra solo a los grados inferiores y abstenerse de colocarla en posiciones directivas. De acuerdo a la división de tareas que propuso, las mujeres tampoco podían llevar adelante la obra nacionalizadora, tarea que en la visión de la época era un objetivo central de la escuela. En uno de sus informes como director de la Escuela Normal de Mercedes, Mercante exhortó enfáticamente al ministro de Justica e Instrucción Pública de los peligros que suponía confiar el proyecto de la educación común solo a las mujeres (Mercante, 1909: 477).

Mercante observaba en la ausencia de varones un "problema social" que el Estado debía corregir con políticas específicas. No casualmente, la revista que dirigió apoyó el proyecto de ley que se presentó en la legislatura de la provincia

38 En sintonía con los argumentos económicos y morales sobre la ventaja de hacer reposar la docencia en las mujeres, el Estado argentino también implementó políticas que favorecieron la feminización: progresivamente se inauguraron menos escuelas normales exclusivas para varones creando escuelas mixtas que en la práctica eran prácticamente de mujeres y, en 1892 , se suprimieron las becas a los varones alegando que estos no permanecían en la docencia y en su lugar se otorgaron a mujeres. Luego se restituyeron, pero no se actualizaron sus montos. (Rodríguez, 2021)

39 Sobre la feminización del magisterio existe una amplia bibliografía que se ha nutrido de nuevas perspectivas en los últimos años. Las nuevas investigaciones han subrayado el papel a veces ambiguo que esta ocupación tuvo para la emancipación de la mujer: por un lado, afirmó su rol más allá de la esfera doméstica, pero al mismo tiempo condicionó esa libertad a un rígido repertorio de reglas morales, conductas esperadas y estéticas aceptadas. Entre los trabajos pioneros cabe mencionar Morgade (1997) y Yannoulas (1996). De más reciente aparición se destacan entre otros: Caldo (2014; 2019); Caldo y Vignoli, (2016); Vignoli (2011; 2014); Fiorucci (2016); Billorou (2016); Lionetti (2018); Becerra (2019); Rodríguez (2021). 
de Buenos Aires en 1907 que buscaba distribuir las becas para las escuelas normales en partes iguales entre varones y mujeres. En una nota sin firma se señalaba que los afanes "por despoblar las escuelas normales del elemento varón" los "pagaría caro el país: generaciones de jóvenes sin carácter, holgazanes sin convicciones, perturbadores sin propósitos”. Esto tenía lugar por “dejar exclusivamente en manos de la mujer, ese período difícil de los 9 a 15 años que define la conducta del hombre y su destino" (Becas, 1907: 326). Luego Mercante sería el responsable intelectual de la reforma Lamas ya mencionada que redistribuyó -mientras estuvo vigente- las becas hacia los varones. Como es de imaginarse, la posición de Mercante no fue aislada en las páginas de esa revista. Por ejemplo, en el mismo número en que este publicó su visión contraria a la feminización indiscriminada, también apareció un escrito firmado por el inspector Reyes Salinas donde advirtió como "un verdadero peligro para el magisterio y para la educación [el] predominio de la mujer en las filas de los educadores." (Salinas, 1908: 416). En 1907 las páginas de la revista aplaudieron el nombramiento de un varón como director de una escuela normal en tanto "la experiencia parece haber demostrado la necesidad de que sea un hombre quien dirija una institución” (Escuela Normal de Flores, 1907: 502).

Lugones también se involucró en esta discusión en su obra Didáctica, publicada como dijimos antes en serie en El Monitor de la Educación Común. Allí el escritor alertó sobre el "funesto resultado de una enseñanza nacional confiada exclusivamente a las mujeres" (Lugones, 1909b: 337). Para este escritor no había dudas que la mujer era un ser intelectualmente inferior por sus "peculiaridades fisiológicas" (Lugones, 1909b: 486). En ese texto Lugones afirmó que las mujeres pasaban "su vida intelectual en una semi-infancia que perpetuamente las induce a considerar como una demasía el acto de pensar por sí mismas". Allí alegó también que estas adolecían de "concepto de justicia y de integridad" propio de los varones; eran "impulsivas" obrando por "afecto y antipatía", por lo que su naturaleza era "de espíritu menos moral que el hombre”. Al igual que Mercante, sostenía que las mujeres podían enseñar, pero no más allá de cuarto grado. Es decir que debían tener un rol subordinado en el proyecto educativo. Al mismo tiempo Lugones postulaba la necesidad de acotar la educación de las mujeres. Consideraba "un grave error el acceso discrecional de las mujeres a todos los estudios" porque esto llevaba al intelectualismo femenino, opuesto a la naturaleza y de consecuencias negativas. El feminismo era para Lugones una "perturbación" producto de dicho intelectualismo. Es preciso aclarar que Lugones tenía una opinión negativa del trabajo femenino en general. La enseñanza de las mujeres en la escuela debía adaptarse a lo que eran sus funciones primordiales. "Los conocimientos que en el hombre han de ser fundamentales y susceptibles de ilimitado desarrollo, deben quedar reducidos en ella a nociones generales de aplicación constante y práctica. La buena esposa no necesita más, y las escuelas de un país pueden darse por bien servidas, creyendo llenada su misión hasta lo perfecto, si forman buenas esposas", concluía Lugones en 1909 (Lugones, 1909c: 421).

Su oposición al trabajo femenino lo llevó a postular el magisterio como una opción solo para jóvenes humildes. Lugones abrevó en un lugar común de la época donde 
el trabajo femenino era visto como algo excepcional y en el mejor de los casos transitorio: hasta el casamiento o la maternidad..$^{40}$ Lugones era un fiel creyente de lo que se conoce como la ideología de la domesticidad. En la Argentina de principios de siglo, diversos actores sociales observaban con animosidad del trabajo femenino en tanto señalaban la maternidad "como una identidad femenina exclusiva y por lo tanto incompatible con cualquier otra actividad, en especial la laboral" (Queirolo, 2008). La mujer debía ocuparse del hogar y las tareas domésticas y sería el varón el que realizaría el trabajo asalariado y se ocuparía de las obligaciones cívicas en el contexto de la calle. Dentro de ese imaginario una de las mayores críticas se concentraba contra el trabajo fuera del hogar. Lugones consideraba un error la producción excesiva de maestras mujeres porque éstas se dedicarían al estudio y no al "aprendizaje doméstico". Pronosticaba como un riesgo no sólo "la formación de un país afeminado" sino también la de "un proletariado femenino" sin puestos laborales y con un destino incierto (Lugones, 1910a). Entre la mujer maestra o la mujer, el escritor sostenía que el Estado "debe cuidar siempre a la mujer con preferencia: ella es más importante que la profesora” (Lugones, 1909a: 338). En una argumentación que combinaba lo fisiológico con lo social, Lugones sostuvo que la presencia de las mujeres socavaba uno de los pilares sobre el que se asentaba el proyecto educativo: el laicismo. Por sus características, las mujeres estaban sujetas "más que los hombres al respeto de las convenciones mundanas, entre las cuales figura el culto como elemento de distinción social”. La situación se agravaría al dejar la dirección de las escuelas en manos de mujeres porque éstas usarían la escuela para propagar el catolicismo (Lugones, 1909a: 483). Cabe aclarar que la dirección de una escuela fue una de las primeras ocupaciones donde las mujeres tuvieron autoridad sobre los hombres. Este dato no fue pasado por alto por Lugones, quien declaró que éstas actuaban aún peor "cuando tienen a sus órdenes personal masculino".

Este tipo de argumentos también fueron proferidos por figuras menos conocidas pero que tenían responsabilidad directa en la gestión de la educación. Por ejemplo, en 1912, el inspector de escuelas primarias Amable Álvarez publicó en El Monitor de la Educación Común un extenso artículo sobre el estado de la educación primaria en el país. Luego de describir cómo se daba la feminización en otros estados nacionales concluyó que "el país [tenía] un grave problema que resolver" ya que la educación de "los niños de cierta edad requiere, fuera de duda, la acción directriz del maestro hombre para modelarles un carácter viril, tan indispensable en la vida ulterior". Álvarez advirtió que si bien la preeminencia de mujeres en el magisterio era una característica en todos los países del mundo no lo era "en la desproporción que exist[ía] en la República Argentina" (Álvarez, 1912)..$^{41}$ En la revista del CNE es posible identificar una clara preocupación por dar cuenta de cómo se daba la feminización en otros contextos nacionales. Algunos

40 Sobre el tema del trabajo femenino ver Aguilar (2014).

41 El Monitor de la Educación Común no solo compilaba opiniones adversas al magisterio femenino. También publicó artículos con opiniones favorables sobre la figura de la mujer maestra. Por ejemplo, en un texto firmado por el filólogo español docente en la Escuela Normal de Profesoras de la ciudad de Buenos Aires, Miguel de Toro y Gómez, este afirmó las ventajas de la docencia femenina concluyendo "que los gobiernos, celosos del progreso y la cultura en todos los órdenes, [deben fomentar] cada vez más el reclutamiento de la mujer para las funciones del magisterio". 
de los textos eran meramente informativos: se reproducían los porcentajes de docentes varones y docentes mujeres en cada país (La mujer en la enseñanza, 1910: 23). Otros recogían las conclusiones que se hacían de este fenómeno en otros contextos. Por ejemplo, una pequeña viñeta transcribía las apreciaciones al respecto del periódico Excelsior de Milwaukee donde se afirmaba que dada la supremacía numérica de las mujeres en la educación en Estados Unidos no era “extrañar que la población masculina en [ese] país [se] afeminara” (Ecos de todas partes, 1909: 921) ${ }^{42}$.

Gálvez también participó de esta discusión. El autor no asociaba en La maestra normal los males del normalismo a la presencia mayoritaria de las mujeres; por el contrario, varias son las figuras masculinas que fueron objeto de crítica en su novela. No obstante, podemos interpretar este texto como contrario a la feminización porque realizaba allí una operación que minaba la representación del magisterio como ocupación decente. Como sabemos, dicho aspecto era una de las razones sobre las que se había fundado la feminización del cuerpo docente. En contraposición a las representaciones que despojaban de elementos disruptivos al normalismo, el escritor nacionalista lo asociaba a una serie de males donde las mujeres quedaban expuestas a situaciones inmorales. La escuela normal que Gálvez describió era un espacio corrompido, escenario de relaciones impropias entre hombres y mujeres. En su lugar de trabajo la maestra interactuaba con varones que no eran de su familia. Es esa interacción la que una y otra vez reprueba Gálvez. Las relaciones que se daban entre maestros de distinto sexo aparecen teñidas en la novela de indecencia. Es este el caso de la historia que estructura el texto: la de los maestros Raselda y Solís, pero no la única. Esta inmoralidad se repite, por ejemplo, en la relación del director y la regente. El clima de la escuela normal es tal que la mayoría de las docentes que pueblan la novela de Gálvez son inmorales, tienen mala formación, desprecian su tarea. Esto es así para el escritor nacionalista porque el sistema de enseñanza público ha abandonado los valores católicos y el normalismo se ha convertido en una profesión de mujeres sin vocación. La independencia que otorga a las mujeres el ejercicio de una profesión y, por ende, el goce de un salario también es un aspecto que aparece connotado negativamente en el relato. En una escena donde Raselda está a punto de sobrepasar los límites del decoro, esta se convence de que puede escuchar todo porque es "una maestra, es decir una mujer independiente que podía oírlo todo” (Gálvez, 1914). No hay dudas de que la maestra representaba un nuevo tipo de mujer. Reflexionando retrospectivamente sobre su labor, una de las maestras norteamericanas convocadas por Sarmiento para enseñar en Argentina a fines del siglo XIX (Jennie E. Howard), advertía sobre el efecto del normalismo en las elecciones vitales de las mujeres de ese tiempo: "la educación [significó] mayor libertad para disponer de sus vidas" y esta les abrió otras posibilidades que "el matrimonio, el que había

42 El tema de las mujeres como educadoras estaba atado a las visiones sobre la educación de la mujer y sobre su rol en la sociedad. Si bien es posible observar cierto consenso que se debía educar a la mujer había disonancias en cuanto si la preparación debía estar orientada en gran medida para el hogar. Este debate también estaba vinculado a una preocupación por la coeducación. Las páginas de las publicaciones educativas muestran que en las primeras décadas del siglo XX el debate sobre si mujeres y varones podían recibir el mismo tipo de educación elemental no había sido saldado en la Argentina. 
sido antes entonces su único camino" (Howard, 1931:112). ${ }^{43}$ Según Pablo Pineau, el salario que la maestra recibía a cambio de su trabajo la asimilaba a la imagen de la meretriz, en tanto a las prostitutas se las condena por cobrar una tarea que les era obligatoria por el "deber conyugal” (Pineau, 2005). Es decir que Gálvez se oponía a la feminización porque asociaba el magisterio con la corrupción moral de las mujeres y con un nuevo modelo de mujer que desaprobaba.

Cabe preguntarse qué dijeron las maestras mujeres de estas críticas considerando además que ellas consumían muchas de las publicaciones donde se las cuestionaban. En 1909, aproximándose a los festejos del centenario de la independencia, se discutió la posibilidad de erguir un monumento a la figura del docente. Raúl B Díaz, el primer inspector de territorios nacionales, realizó un bosquejo escrito de cómo realizar esa estatua. Allí propuso al escultor la representación de un varón de "frente abultada y amplia arriba de grandes ojos de mirar sereno, hondo y alegre" vestido con un "traje equidistante entre los extremos de la ostentación ofensiva y de la humildad deprimente". El monumento proyectado era el de un varón cuando para ese entonces las mujeres eran claramente mayoritarias en la profesión. Este no es un dato de color, sino que es sintomático de una profesión que en la práctica era femenina pero que se escribía "en masculino", como advirtió Lucía Lionetti. Generalmente cuando se hablaba de la docencia se referían a varones como se puede deducir de las intervenciones aquí tratadas. Al mismo tiempo, si bien se comparaba a la figura de la maestra con la de la madre, las representaciones ideales del docente eran muchas veces representaciones ideales del maestro varón destacándose en una buena dosis características y/o figuras masculinas. A la hora de presentar al maestro ideal se comparaba al docente con el del soldado, el apóstol, un héroe o un sacerdote. Es decir que la feminización cuantitativa del magisterio no estuvo acompañada de una feminización simbólica en términos acordes. Son escasas, por lo tanto, las voces femeninas que en esta etapa opinan en la discusión. Una de las figuras que se refirió al magisterio femenino, pero desde una posición que puso el eje en el tema laboral en sentido más amplio, fue Cecilia Grierson. La primera médica mujer en Argentina, recibida de maestra y luego profesora normal en la primera Escuela de maestras de la Capital Federal, observó con cierto pesar la imagen del magisterio como una ocupación de mujeres. Con desilusión Grierson afirmó en 1902 que "cuando una mujer de cierta clase social necesita trabajar en la Capital ¿Qué trabajo elige? Si solo ha frecuentado la escuela primaria: es la costura, si ha concurrido a la una escuela normal: es el profesorado" (Grierson, 1902: 184). Grierson insistió en la necesidad de propagar la educación técnica para la mujer de modo que estas pudieran ejercer distintos empleos. Aunque aceptaba el papel que había tenido la escuela normal como espacio para elevar "la instrucción de la mujer" argumentó que las mujeres se habían inclinado "en exceso" por esta carrera "por ser el profesorado la única brecha abierta a las que se consideraban con capacidad para formarse una carrera independiente y con resultados prácticos” (Grierson, 1902: 167). Grierson vaticinó en 1902 -como de hecho sucedió unos años más tarde- que esto supondría problemas concretos para las mujeres a la hora de 
insertarse laboralmente. Identificó al profesorado (al igual que la costura) como profesiones "casi agotadas donde solo las privilegiadas [lograrían] ganarse la subsistencia (Grierson, 1902: 182). Además, no consideraba el trabajo cotidiano de la docencia como emancipador. En una crónica de su vida afirmó que había optado por dejar la docencia para encarar "otra carrera en que [la] actividad no fuera aquilatada por horas" y "vislumbraba en la carrera de medicina una profesión menos sometida a horario". ${ }^{4}$

En el primer Congreso Femenino Internacional celebrado en Buenos Aires en 1910, se pueden registrar numerosas reivindicaciones del trabajo femenino y de la capacidad de las mujeres para encarar cualquier labor científica y/o profesional, aunque el debate se sostuvo en términos generales (Aleixandre, 2010: 338-354). En otras palabras, las mujeres no articularon en ese recinto respuestas directas a lo dicho por sus colegas varones sobre su incapacidad para ejercer la docencia, aunque sí afirmaron a la mujer trabajadora. En el discurso inaugural de ese Congreso la educadora feminista Ernestina A. López, primera doctora en Letras de la Universidad de Buenos y rectora del Liceo de Señoritas de la Capital, figura de la que es lícito imaginar que conocía los dichos de Lugones, sostuvo que "el trabajo femenino como el del hombre puede aplicarse a empresas diversas y también a especulaciones elevadas del espíritu” (López, 2010:65). En la alocución de una de las asistentes al congreso (Dolores B. Bustamante) se reivindicó "a la mujer en el periodismo y en todas aquellas profesiones que tiendan a levantar su espíritu, sin la potestad del hombre" (Bustamante, 2010: 318). La feminista chilena M. Aurora Argomedo subrayó en su discurso la tarea de la maestra y la comparó con la "sublime manifestación del amor de la hija para con la madre patria” (Argomedo, 2010: 84). Como se observó en la introducción, la publicación de La maestra normal sí suscitó algunas reivindicaciones y/o alusiones relativamente más directas como la de Rosario Vera Peñaloza mencionada en la introducción. Otra intervención relacionada fue el artículo aparecido en la revista del CNE de la Doctora en Letras, autora de textos y asidua colaboradora de la publicación, María Velazco Arias. En dicho texto, también publicado en 1915, describió como "las almas retrógradas" las que "lamentaron [...] la incorporación de las mujeres en la docencia diplomada" concluyendo que "la maestra normal egresada de las aulas argentinas lleva[ba] consigo el caudal necesario para docencia en idénticas condiciones que el hombre." (Arias, 1915).

\section{Conclusión}

Las intervenciones aquí recortadas muestran que a la par de su expansión y aceptación de la sociedad civil en la Argentina, la escuela normal fue fuertemente cuestionada, sobre todo por aquellos que la gestionaban y debían apuntalarla. La ubicuidad de la escuela y el progresivo crecimiento del contingente de maestros, junto con su notable feminización, fueron algunas de las causas que promovieron 
el interés de los contemporáneos por el normalismo. Claramente los juicios aquí abordados se pueden relacionar a las visiones alarmistas sobre el proceso modernizador de la sociedad argentina que articularon distintas voces intelectuales en el giro hacia el siglo XX, no obstante, el debate se recorta como un tema en sí mismo que instaló problemas específicos y ocupó a algunas de las plumas más encumbradas del momento. En las intervenciones que aquí se analizaron se argumenta que la escuela normal era mala porque no brindaba una buena formación, su diseño estaba corrompido por la política y había sido hiperpoblada por mujeres. El docente producto de esa institución no podía, por lo tanto, cumplir la tarea que la nación le había encomendado: garantizar una buena escuela. Es preciso no aceptar estas intervenciones como descripciones desinteresadas de la realidad, ni como las únicas representaciones que circulaban,pero sí deben ser tenidas en cuenta a la hora de historizar el normalismo, la escuela primaria y la figura del docente. En este sentido, el trabajo se propone contribuir al entendimiento del contexto en que se construyeron las primeras representaciones de la profesión docente. ${ }^{45}$ La bibliografía sobre las profesiones advierte sobre los límites de la profesionalización en el caso de la docencia primaria al punto que se la considera como una semiprofesión. ${ }^{46}$ Esto es así, entre otras cosas, porque es un trabajo asalariado creado por el Estado, horizontal en lo que se refiere a las posiciones (es decir sin carrera), caracterizado por una educación que generalmente no es universitaria y sin mecanismos de clausura en lo que respecta al acceso. El caso argentino mostraría cómo esas limitaciones (intrínsecas a la profesión misma) se potenciaron con los discursos aquí estudiados para alimentar la descalificación del docente primario y en especial de la figura de la maestra mujer. Sin ahondar en el contenido de esas críticas, Ricardo González Leandri señaló al respecto que estas limitaron también el papel de la elite docente en las decisiones de política educativa. Al deslegitimar a la figura del maestro y de la maestra, los propios normalistas encumbrados (entre estos se encuentran claramente los inspectores aquí citados) también socavaron su propio rol. Sus "críticas exacerbadas" y su "falta de cohesión profesional” tendieron -según González Leandri- a estratificar en exceso a la profesión y a debilitarla en su competencia con otros sectores. Esto explicaría su escasa presencia en los roles más prominentes de la burocracia educativa.

Las intervenciones estudiadas también permiten problematizar la idea ampliamente aceptada que la docencia era a principios del siglo XX un trabajo "socialmente prestigioso" para pintar una realidad más contradictoria. ${ }^{47} \mathrm{Si}$ bien es cierto que la escuela era un lugar donde la mujer se emancipaba y donde efectivamente alcanzaba un prestigio y una autoridad social que difícilmente podía hallar en otro ámbito, no fue este un proceso exento de tensiones. En los últimos años varias investigaciones han advertido que al mismo tiempo que la docencia abría nuevas posibilidades, posicionaba a las mujeres en un lugar y les adjudicaba un rol que

45 A la par de estas representaciones críticas sobre la figura de la maestra y el maestro se construyeron representaciones ideales acompañadas de una alta valoración de la tarea docente que por su carácter irrealizable muchas veces también contribuyeron a la desjerarquización de la profesión.

46 Una revisión sobre esta literatura se puede leer en Serón (1992).

47 Entre las versiones que subrayan el prestigio y reconocimiento que recibían las maestras se puede mencionar entre otras Sarlo (1998: 68); Bracamonte (2011) y Lionetti (2018). 
las hacía objeto del escrutinio y la censura pública. Los discursos aquí recortados permiten notar que muchos intelectuales observaban con recelo el protagonismo que alcanzaban las mujeres en la esfera pública a través de la docencia. Como también fue señalado aquí, el cuestionamiento a la feminización del magisterio se instalaba en un contexto de inquietud frente al trabajo femenino donde se creía que la mujer, definida por su cuerpo y en particular por su función reproductora, debía limitarse al ámbito restringido de hogar (Aguilar, 2014). El trabajo discute con la bibliografía que ha reconstruido la feminización del magisterio como un proceso sin grandes tensiones (Fischman, 2007:347). Gustavo Fischman describe la relación entre una fuerza de trabajo femenina y el resto de la sociedad como una "relación romántica", la cual comenzaría a resquebrajarse solo a fines del siglo veinte (Fischman, 2007: 362). Silvia Yannoulas, quien ha estudiado en detalle este tema, se refiere a la feminización del magisterio como un "proceso sin conflictos... donde los actores masculinos involucrados concordaban y apelaban al ingreso de las mujeres a la práctica pedagógica" (Yannoulas, 1996: 44). No se puede negar la flagrante contradicción que suponía hacer a las mujeres responsables de crear al ciudadano mientras que éstas eran privadas del derecho a una ciudadanía plena. Si bien su elección como educadoras se podía explicar por razones pedagógicas y prácticas, e incluso cuando se condecía con ciertas visiones sobre la naturaleza femenina, ese tejido de ideas que pretendía acotar el lugar de la mujer en la sociedad seguía operando mientras el magisterio se feminizaba. No es casual, por lo tanto, que se observara con sospecha el ingreso de éstas en gran proporción a un ámbito laboral que les otorgaba independencia material y simbólica. 


\section{Bibliografía}

" Aguilar, P. (2014). El hogar como problema y como solución. Una mirada genealógica de la domesticidad a través de políticas sociales, Argentina 1890-1940. Buenos Aires: Ediciones del CCC Centro Cultural de la Cooperación Floreal Gorini.

" Aleixandre, C. (2010). La mujer en medicina. Centenario Primer Congreso Femenino Internacional de la República Argentina. Mayo de 1910, 338-354.

" Alliaud, A. (2007). Los maestros y su historia. Los orígenes del magisterio argentino. Buenos Aires: Granica.

" Álvarez, A. (1912). La instrucción primaria en 1911. El Monitor de la Educación Común, año 30, n. 473.

" Anderson, K. (2015). The Los Angeles State Normal School, UCLAS's Forgotten Past, 18811919. California.

" Anexos de Instrucción Pública (1905).

" Argentina. Informe presentado al Ministerio de Instrucción Pública por el Dr. José María Gutiérrez (1896).

" Argentina. Informe de Instrucción Pública (1910).

" Argentina. Inspección General de Enseñanza Secundaria y Normal (1904). Memoria Presentada Al Congreso Nacional por El Ministro de Justicia e Instrucción Pública, tomo 2. Anexos De Instrucción Pública.

"Argentina. Plan de estudios de los colegios nacionales y escuelas normales (1904). Memoria presentada al Congreso Nacional de por el Ministro de Justicia e Instrucción Pública, tomo 2.

" Argentina. Ministerio Justicia e Instrucción Pública Departamento De Instrucción Pública (1916). Memoria del Ministerio Justicia e Instrucción Pública Departamento De Instrucción Pública, tomo 3.

" Argentina. Inspección General de Enseñanza Secundaria y Normal (1916). Memoria del Ministerio de Justicia e Instrucción Pública.

" Argomedo, A. (2010). La moralidad y el trabajo como fin supremo de la instrucción. Centenario Primer Congreso Femenino Internacional de la República Argentina Mayo de 1910.

" Arias, M. (2015). La maestra normal. Trabajo leído en homenaje que el Consejo Escolar VII rindió a los maestros jubilados del distrito. El Monitor de la Educación Común, año 34, n. 514 , tomo 55 .

" Artieda, T. (1993). El Magisterio en los Territorios Nacionales: el caso de Misiones. En A. Puiggrós (dir.). La educación en las provincias y en Territorios Nacionales (1885-1945). Buenos Aires: Editorial Galerna.

" Becas (1907). Archivos de Pedagogía y Ciencias Afines, tomo II.

" Becerra, M. (2019). Un cuarto propio: relaciones de género, amor y magisterio en la Argentina de inicios del siglo XX. Propuesta Educativa, 28(51), 42-60.

" Berra, F. (1901). Los principios constitutivos de la enseñanza común. Discurso pronunciado por el Doctor Francisco A. Berra en el Congreso Pedagógico Argentino de 1900. El Monitor de la Educación Común, año 21, n. 339, tomo 17. 
" Billorou, M. (2016). Mujeres que enseñan no solo en las aulas. Docentes en el interior argentino en la primera mitad del siglo XX. Historia de la Educación Anuario, 17(2), 57-79.

" Bracamonte, L. (2011). Mujeres, trabajo y educación a principios del siglo XX: las maestras en la prensa católica del sudoeste bonaerense argentino. Diálogos, Revista Electrónica de Historia, 12(1), 101-127.

" Bunge, C. (1909). La Educación. Valencia: F. Sempere y Compañía Editores.

" Bustamente, D. (2010). La evolución femenina. Centenario Primer Congreso Femenino Internacional de la República Argentina Mayo de 1910.

"Caldo, P. (2014). No parecían mujeres pero lo eran. La educación femenina de las maestras, Argentina 1920-1930. Revista Historia y Sociedad.

" Caldo, P. y Vignoli, M. (2016). Presentación: Dossier. Maestras, prácticas, género e historia: hacia una historia de la educación con mujeres en los tiempos de la consolidación de los sistemas educativos. Anuario.

"Caldo, P. (2019). Solteras o debidamente casadas. Aproximaciones a una arista poco explorada en la historia de las maestras argentinas, 1920-1950. Arenal. Revista de Historia de las Mujeres.

" Carli, S. (1995). Entre Ríos. Escenario Educativo 1883-1930. Paraná: Facultad de Ciencias de la Educación.

" Castro, M. (2010). Para combatir ese extraviado prurito del extranjerismo: políticos católicos, la cuestión nacional y el Consejo Nacional de Educación en torno al Centenario. En M. Tato y M. Castro (comps.). Del Centenario al peronismo. Dimensiones de la vida política argentina. Buenos Aires: Imago Mundi.

"Castro, M. (2017). De regímenes pasados y regeneradores: elites, congreso y coaliciones políticas a finales del orden conservador. Investigaciones y Ensayos, n. 65, 89-112.

"Congreso Internacional de Enseñanza Primaria (30 de setiembre de 1910). El Monitor de la Educación Común, año 29, n. 453.

"Decreto orgánico Escuelas Normales - 17 de mayo de 1911 (30 de junio de 1915). El Monitor de la Educación Común, n. 510, tomo 53.

" Dussel, I. (1997). Currículum Humanismo y Educación democrática. Buenos Aires: Flacso.

"Ecos de todas partes (31 de diciembre de 1909). El Monitor de la Educación Común, n. 444 , tomo 31.

"El arte de enseñar (31 de octubre de 1900). El Monitor de la Educación Común, año 20, n. 332 , tomo 17.

" El Monitor de la Educación Común (1905).

" El Monitor de la Educación Común (31 de marzo de 1917). Año 35, n. 531, tomo 60. Buenos Aires.

" Encuesta que elige a Leopoldo Lugones como la voz literaria del momento (1903). El Gladiador.

"Escuela Normal de Flores (1907). Archivos de Pedagogía y Ciencias Afines, tomo II.

"Estadística general de la enseñanza primaria en Argentina (31 de marzo de 1915). El Monitor de la Educación Común, año 35, tomo 60.

" Fiorucci, F. (2014). Maestros para el sistema de educación pública. La fundación de escuelas normales en Argentina (1890-1930). Revista Mexicana de Historia de la Educación, 2(3), 25-45. 
" Fiorucci, F. (2016). País afeminado, proletariado feminista, mujeres inmorales e incapaces: la feminización del magisterio en disputa. Historia de la Educación. Anuario, 17(2), 120137.

" Fiorucci, F. (2018). Raúl B Díaz: inspector e intelectual de Estado. En L. Rodríguez y G. Soprano (eds.). Profesionales e intelectuales de Estado. Análisis de perfiles y trayectorias en la salud pública, la educación y las fuerzas armadas. Rosario: Prohistoria.

" Fiorucci, F. (2019). La expansión del normalismo: debates intelectuales y representaciones persistentes (1884-1920). Mimeo.

" Fischman, G. (2007). Persistance and ruptures in the feminization of teaching and teacher education in Argentina. Gender and Education, 19(3).

" Friedel, V. (1912). La preparación profesional de los maestros en las Universidades. EI Monitor de la Educación Común, año 30, n. 473.

" Gálvez, M. (1914). La maestra normal. Buenos Aires: Sociedad Cooperativa Nosotros.

" Goldchluk, G. (1995). Literatura Argentina y nacionalismo: Gálvez, Fogwill, Saer y Aira. La Plata: UNLP.

" González Leandri, R. (2001). La elite profesional docente como fracción intelectual subordinada: 1852-1900. Anuario de Estudios Americanos, 8(2), 513-535.

" Goy, H. (1919). El maestro y la Universidad. El Monitor de la Educación Común, año 37, n. 526.

" Grierson, C. (1902). Educación Técnica de la mujer. Informe presentado al Sr Ministro de Instrucción Pública de la República Argentina. Buenos Aires: Tipografía de la Penitenciaría Nacional.

" Gvirtz, S. (1991). Nuevas y viejas tendencias en la docencia (1945-1955). Buenos Aires: Centro Editor de América Latina.

" Howard, J. (1931). In Distant Climes and Other Years. Buenos Aires: The American Press.

"Jijena, D. (1912). Presupuesto para 1913. El Monitor de la Educación Común, año 30, n. 474.

" Kohn Loncarica, A. (1976). Cecilia Grierson, Vida y obra de la primera medica argentina. Buenos Aires: Editorial Stilcograf.

" Labaree, D. (2008). An uneasy relationship: the history of teachers in the university. Universidad de Stanford.

" Lafarga Galván, L. (2012). Los inicios de la formación de profesores en México. História da Educacao, 16(38), 43-62.

" La instrucción primaria en 1911 (1912). El Monitor de la Educación Común, año 30, n. 473.

" La mujer en la enseñanza (31 de marzo de 1910). El Monitor de la Educación Común, año 39, n. 44.

" Lanzilotta, M. (2012). Maestros y bachilleres en el Territorio Nacional de La Pampa. Instituciones, grupos intelectuales y dinámica política (1909-1943). En P. Laguarda y F. Fiorucci. Intelectuales, cultura y política en espacios regionales (siglo XX) (pp. 153-172). Rosario: Prohistoria Ediciones.

" La refundación de las escuelas normales (3 de febrero de 1900). La Nación, p. 5.

" Larsen, M. (2011). The Making and Shaping of the Victorian Teacher. A Comparative New Cultural History. Londres: Palgrave. 
" Latzina, F. (1909). Introducción. Censo 1909.

" La población de la república considerada según sus profesiones (1914). Tercer censo Nacional, tomo 1.

" Legarralde, M. (2019). Inspectores. En F. Fiorucci y J. Vismara (eds.). Palabras claves en la historia de la educación argentina (pp. 205-208). Buenos Aires: UNIPE.

" Lionetti, L. (1999). Un campo de lucha por encauzar la 'moral': entre la resistencia y la asimilación, (1900-1920). En P. Gonzalbo Aizpuru (Comp.). Familia y Educación en Iberoamérica (pp. 223-245). México: El Colegio de México.

" Lionetti, L. (2007). La misión política de la escuela pública. Formar a los ciudadanos de la república (1870-1916). San Martín: Miño y Dávila Editores.

" Lionetti, L. (2018). Revisitando la tradición normalista. Diálogos entre el peso de la formación y la perspectiva de género. En L. Rodríguez y G. Soparano (eds.). Profesionales e intelectuales de Estado. Análisis de perfiles y trayectorias en la salud Pública, la educación y las fuerzas armadas (pp. 69-94). Rosario: Prohistoria.

" López, E. (2010). Sesión Inaugural. Discurso de la Dra. Ernestina A. López. Centenario Primer Congreso Femenino Internacional de la República Argentina Mayo de 1910.

" Lugones, L. (1909a). Didáctica. Escuelas normales. El Monitor de la Educación Común, año 28 , n. 440 , tomo 30.

" Lugones, L. (1909b). Didáctica. Personal Docente. El Monitor de la Educación Común, año 28, n. 434 , tomo 30 .

" Lugones, L. (1909c). Didáctica. Didáctica - El alumno en la escuela. El Monitor de la educación Común, n. 438, tomo 29.

" Lugones, L. (1910). Situación y alcance de los ramos. El Monitor de la Educación Común, año 29 , n. 447, tomo 32.

" Lugones, L. (1915). En defensa de la Maestra Normal. La Nación.

" Mercante, V. (1906). Colegios Nacionales - Preparación de los alumnos. Archivos de Pedagogía y Ciencias Afines, tomo I.

" Mercante, V. (1908). La mujer Moderna. Archivos de Pedagogía y Ciencias Afines, tomo IV.

" Mercante, V. (1909). Informe de la Dirección de la Escuela Normal de Mercedes. Memoria Presentada al Congreso Nacional por el Ministerio de Justicia e Instrucción Pública, Anexos de Instrucción Pública.

" Morgade, G. (1997). La docencia para las mujeres: una alternativa contradictoria en el camino de los saberes legítimos. En G. Morgade (comp.) Mujeres en la educación. Género y docencia en Argentina (1870-1930) (pp. 67-114). Buenos Aires: Miño y Dávila.

" Ogren, C. (2005). The American State Normal School. An instrument of Great Good. Londres: Palgrave.

"Paz, J. (1916). Informe Escuela Número 8 de la Capital Federal. Memoria del Ministerio de Justicia e Instrucción Pública Departamento de Instrucción Pública.

"Pineau, P. (2005). Amores de mapoteca. Lujuria y normalismo en la historia de la educación argentina. Cuadernos de pedagogía, n. 13, 79-88.

" Pinkasz, D. (1992). Orígenes del profesorado secundario en la Argentina. En C. Braslavsky y A. Birgin (comps.). Formación de profesores. Impacto, pasado y presente. Buenos Aires: Miño y Dávila.

" Pizzurno, P. (1902). Enseñanza Secundaria y Normal Informe Correspondiente a 19011902. Buenos Aires: Taller Tipográfico de la Penitenciaría Nacional. 
" Pizzurno, P. (1906). Reformas en la organización de los estudios normales: proyecto expuesto en la reunión de los profesores de la Escuela N. El Monitor de la Educación Común, año 27, n. 408.

"Ponce de León, M., Ren, F. y Uzcátegui Pacheco, R. (2020). Las escuelas Normales en Venezuela. Modelos pedagógicos en su desarrollo institucional (1870-1980). Revista de Historia Americana y Argentina, 55(1), 35-62.

"Queirolo, G. (2008). Malos pasos, caídas, sacrificios, entregas: representaciones literarias del trabajo femenino asalariado (Buenos Aires, 1919-1939). En S. C. Mallo y B. I. Moreyra (coord.). Miradas sobre la historia social en la Argentina en los comienzos del siglo XXI. Córdoba: Centro de Estudios Históricos "Prof. Carlos S.A Segretti".

"Queirolo, G. (2018). Mujeres en las oficinas, Trabajo, Género Y Clase en el Sector Administrativo (Buenos Aires, 1910 -1950). Buenos Aires: Biblos.

"Rodríguez, L. y Soprano, G. (2018). De las profesiones liberales y los intelectuales contra el Estado, al estudio de los profesionales e intelectuales de Estado. En L. Rodríguez y G. Soprano (eds.). Profesionales e intelectuales de Estado. Análisis de perfiles y trayectorias en la salud pública, la educación y las fuerzas armadas (pp. 9-67). Rosario: Prohistoria.

" Rodríguez, L. (2019). Cien años de normalismo en Argentina (1870-1970). Apuntes sobre una burocracia destinada a la formación de maestros. Ciencia, Docencia y Tecnología, 30 (59), 200-235.

" Rodríguez, L. (2019). Ministerio y ministros de la nación. En F. Fiorucci y J. Vismara. Palabras Claves en la historia de la educación argentina (pp. 227-232). Buenos Aires: UNIPE.

" Rodríguez, L. (2021). Maestros y maestras la cuestión de género: planes de estudio, salarios y feminización (Argentina, 1870, 1914). Descentrada, 5 (1).

" Rossi, A. (1937). La escuela Normal Nacional de San Fernando. Sus orígenes. Buenos Aires: Porter Hermanos Impresores.

"Salinas, W. (1908). El magisterio y su preparación. Archivos de Pedagogía y Ciencias Afines, tomo IV.

"Salvatore, R. (2016). Burocracias expertas y exitosas en Argentina: Los casos de educación primaria y salud pública (1870-1930). Estudios Sociales del Estado.

"Sánchez Sorondo, M. (1916). La instrucción obligatoria. El Monitor de la Educación Común, año 34, n. 517.

"Sarlo, B. (1998). La máquina cultural. Maestras, traductoras y vanguardistas. Buenos Aires: Ariel.

" Sarmiento, D. (1849). Educación Popular.

"Serón, A. (1992). Perspectivas teóricas sobre la profesión docente. Revista Complutense de Educación, 3(1).

"Serrano, S., Ponce de León, M. y Renfiga, F. (eds.) (2013). Historia de la Educación en Chile (1810-2010). Tomo II. Santiago de Chile: Taurus.

"Southewell, M. (2014). Cien años de Ciencias de la Educación: Entre los fundamentos de la pedagogía y el diálogo con el sistema educativo. Archivos de Ciencias de la Educación, $8(8), 1-32$.

"Suásnabar, C. (2013). La institucionalización de la educación como campo disciplinar: Un análisis desde la perspectiva de la historia social de las ciencias sociales. Revista Mexicana de Investigación educativa, 43(59).

"Suásnabar, C. (2018). Francisco Berra y la primera cátedra de Ciencia de la Educación: los 
orígenes del pensamiento pedagógico entre el naturalismo y el positivismo. Historia de la Educación. Anuario, 19(1), 4-23.

"Tedesco, J. (2009). Educación y sociedad en la Argentina (1880-1945). Buenos Aires: Siglo Veintiuno.

"Vera, S. (1902). Informe de la Escuela Normal de Rio Cuarto. Córdoba.

"Vera Peñaloza, R. (1915). El Monitor de la Educación Común, n. 516, tomo 55, 493.

"Vignoli, M. (2011). Educadoras, lectoras y socias. La irrupción de las mujeres en un espacio de sociabilidad masculino. La Sociedad Sarmiento de Tucumán (Argentina) entre 1882 y 1902 . Secuencia.

"Vignoli, M. (2014). Trayectoria educativa y prácticas de sociabilidad de una tucumana de entre siglos: Margarita Todd, maestra normal. Historia y memoria.

"Yannoulas, S. (1996). Educar: ¿Una profesión de mujeres? La feminización del normalismo y la docencia (1870-1930). Buenos Aires: Kapelusz. 